\title{
DCC/NTN1 complex mutations in patients with congenital hypogonadotropic hypogonadism impair GnRH neuron development
}

\author{
Justine Bouilly ${ }^{1}$, Andrea Messina ${ }^{1}$, Georgios Papadakis ${ }^{1}$, Daniele Cassatella ${ }^{1}$, \\ Cheng Xu ${ }^{1}$, James S. Acierno ${ }^{1}$, Brooke Tata ${ }^{2,3}$, Gerasimos Sykiotis ${ }^{1}$, \\ Sara Santini ${ }^{1}$, Yisrael Sidis ${ }^{1}$, Eglantine Elowe-Gruau ${ }^{4}$, Franziska Phan-Hug ${ }^{4}$, \\ Michael Hauschild ${ }^{4}$, Pierre-Marc Bouloux ${ }^{5}$, Richard Quinton ${ }^{6}$, \\ Mariarosaria Lang-Muritano ${ }^{7}$, Lucie Favre ${ }^{1}$, Laura Marino ${ }^{1}$, Paolo Giacobini ${ }^{2,3}$, \\ Andrew A. Dwyer ${ }^{1,8}$, Nicolas J. Niederländer ${ }^{1}$ and Nelly Pitteloud ${ }^{1,4, *}$ \\ ${ }^{1}$ Endocrinology, Diabetes \& Metabolism Service, Centre Hospitalier Universitaire Vaudois (CHUV), Faculty of \\ Biology \& Medicine, University of Lausanne, 1005 Lausanne, Switzerland, ${ }^{2}$ UMR-S 1172-JPArc-Centre de \\ Recherche Jean-Pierre AUBERT Neurosciences et Cancer, University of Lille, 59000 Lille, France, ${ }^{3}$ Laboratory of \\ Development and Plasticity of the Neuroendocrine Brain, Inserm, UMR-S 1172, 59000 Lille, France, ${ }^{4}$ Division of \\ Endocrinology, Diabetology and Obesity, Department of Pediatrics, Centre Hospitalier Universitaire Vaudois \\ Lausanne, 1005 Lausanne, Switzerland, ${ }^{5}$ Center for Neuroendocrinology, Royal Free Campus, University \\ College Medical School, London WC1E6BT, UK, ${ }^{6}$ Institute of Genetic Medicine and the Royal Victoria Infirmary, \\ University of Newcastle-upon-Tyne, Newcastle-upon-Tyne NE13BZ, UK, 'Department of Endocrinology/ \\ Diabetology and Children's Research Centre, University Children's Hospital Zurich, 8091 Zurich, Switzerland \\ and ${ }^{8}$ Institute of Higher Education and Research in Healthcare, University of Lausanne, 1005 Lausanne, \\ Switzerland
}

*To whom correspondence should be addressed at: Endocrinology, Diabetes \& Metabolism Service, Centre Hospitalier Universitaire Vaudois Lausanne, Hôtel des Patients, Avenue de la Sallaz 8, CH-1011 Lausanne, Switzerland. Tel: +41 0213148027; Fax: +41 0213148031; Email: nelly.pitteloud@chuv.ch

\begin{abstract}
Congenital hypogonadotropic hypogonadism $(\mathrm{CHH})$ is a rare genetic disease characterized by absent puberty and infertility due to GnRH deficiency, and is often associated with anosmia [Kallmann syndrome (KS)]. The genetic etiology of CHH is heterogeneous, and more than 30 genes have been implicated in approximately $50 \%$ of patients with CHH. We hypothesized that genes encoding axon-guidance proteins containing fibronectin type-III (FN3) domains (similar to ANOS1, the first gene associated with KS), are mutated in $\mathrm{CHH}$. We performed whole-exome sequencing in a cohort of $133 \mathrm{CHH}$ probands to test this hypothesis, and identified rare sequence variants (RSVs) in genes encoding for the FN3-domain encoding protein deleted in colorectal cancer (DCC) and its ligand Netrin-1 (NTN1). In vitro studies of these RSVs revealed altered intracellular signaling associated with defects in cell morphology, and confirmed five heterozygous DCC mutations in 6 probands -5 of which presented as KS. Two KS probands carry heterozygous mutations in both DCC and NTN1 consistent with oligogenic inheritance. Further, we show
\end{abstract}


that Netrin-1 promotes migration in immortalized GnRH neurons (GN11 cells). This study implicates DCC and NTN1 mutations in the pathophysiology of $\mathrm{CHH}$ consistent with the role of these two genes in the ontogeny of GnRH neurons in mice.

\section{Introduction}

In vertebrates, puberty onset and maintenance of reproductive competence depends on a small population of hypothalamic neurons which secrete gonadotropin releasing hormone ( $\mathrm{GnRH}$ ) (1). This neuropeptide controls, in the anterior pituitary, the production and release of the gonadotropin-luteinizing hormone (LH) and follicle-stimulating hormone (FSH) (2), which stimulate gametogenesis and sex steroid production in the gonads.

During embryonic development, GnRH neurons originate in the olfactory placode and migrate through the nasal mesenchyme using the olfactory/vomeronasal axons as a scaffold to reach their final destination in the basal forebrain $(3,4)$. This migratory process has been well-described in rodents, and is tightly controlled by a complex network of genes encoding molecular cues that drive GnRH neuron motility, cell adhesion and directionality (4). Defects disrupting the genesis, migration of GnRH neurons and/or synthesis and secretion of $\mathrm{GnRH}$ in humans can lead to congenital hypogonadotropic hypogonadism [CHH, MIM \#146110, (5,6)].

$\mathrm{CHH}$ is a rare endocrine disorder ( 1 in 4000) characterized by absent or incomplete puberty resulting in infertility (5). $\mathrm{CHH}$ associated with anosmia (the lack of sense of smell) occurs in $50 \%$ of $\mathrm{CHH}$ patients and is termed Kallmann Syndrome (KS) (7). $\mathrm{CHH}$ is genetically heterogeneous, and both sporadic and familial cases are observed. To date, more than 30 genes have been implicated in the pathophysiology of the disease. The underlying biological mechanisms have been classified into two predominant categories: (I) alteration of the prenatal development and/or migration of $\mathrm{GnRH}$ neurons, generally associated with $\mathrm{KS}$, and (II) disruption of the synthesis, release or signaling of $\mathrm{GnRH}$, commonly associated with normosmic $\mathrm{CHH}$ (nCHH) (5). The low penetrance of most $\mathrm{CHH}$ genes combined with variable expressivity among affected individuals carrying the same gene defect suggests that $\mathrm{CHH}$ is not a strictly monogenic disorder. Indeed, patients harboring mutations in two or more $\mathrm{CHH}$ loci (oligogenicity) have been described $(8,9)$. Additionally, the genetic cause remains unknown in half of cases, indicating that additional CHH loci are yet to be discovered.

The first gene found to be mutated in this disease, ANOS1 (previously known as KAL1), encodes for an extracellular cell adhesion protein containing fibronectin type-III (FN3) domains-an adhesive motif typical of extracellular matrix molecules $(6,10)$. This protein, Anosmin-1, plays a key role in axonal guidance and is involved in the migration of GnRH neurons from the olfactory placode to the brain during development $(10,11)$. The biological relevance of FN3-domain containing proteins in GnRH neuron development is well-illustrated by the fact that the majority of ANOS1 mutations identified in KS are located in regions encoding for FN3 domains. Defects in additional genes encoding these critical domains have also been identified in CHH [i.e. AXL (12), FLRT3 (13)], as well as in other diseases associated with altered neuronal development such as L1CAM in MASA syndrome (14), deleted in colorectal cancer (DCC) in congenital mirror movement (15) and agenesis of the corpus callosum (16), and PTPRQ in autosomal recessive non-syndromic sensorineural deafness (17).

Therefore, we hypothesized that genes encoding axon-guidance proteins containing FN3 domains may be mutated in $\mathrm{CHH}$ patients. We used whole-exome sequencing (WES) to screen a large cohort of $\mathrm{CHH}$ probands and identify novel genetic causes of $\mathrm{CHH}$ among genes encoding axon-guidance proteins containing FN3 domains. Our results demonstrate for the first time several rare and likely pathogenic variants in DCC, a gene encoding FN3-domain protein, and in Netrin-1 (NTN1), its ligand in patients with congenital hypogonadotropic hypogonadism (CHH). In vivo expression of these proteins along the GnRH migratory route in human fetuses and the cellular and molecular functional assays, together with a relevant prevalence of these variants, strongly support the pathogenicity of these mutations in $\mathrm{CHH}$ patients.

\section{Results}

\section{DCC is a novel candidate gene implicated in $\mathrm{CHH}$}

WES of $133 \mathrm{CHH}$ patients (73 $\mathrm{KS}$ and 60 normosmic $\mathrm{CHH}[\mathrm{nCHH}]$ ) revealed 74, 326 high-quality transcript variants. The first step, we evaluated all probands for the presence of mutations in the known $\mathrm{CHH}$ genes. According to the hypothesis that genes encoding proteins containing FN3 domains are potentially mutated in $\mathrm{CHH}$, we filtered our results to include (Supplementary Material, Fig. S1): (I) genes encoding proteins containing FN3domains (Supplementary Material, Table S1), (II) involved in axon guidance (GO: 0007411, Supplementary Material, Table S2), (III) genes implicated in human genetic diseases characterized by alterations in central nervous system neurobiological processes according to OMIM (Table 1), (IV) genes with rare variants [minor allele frequency (MAF) less than $0.1 \%$ in ExAC controls], and conserved nonsense, splice-site, or missense variants predicted to be damaging in at least one of three protein prediction programs (see Methods section). This strategy identified five candidate genes, including ANOS1 (Table 1). Notably, CHH is often associated with specific non-reproductive phenotypes such as congenital mirror movement (CMM), hearing loss and splithand/foot malformations, providing a useful tool to improve the identification of mutations in causal genes (5). In our $\mathrm{CHH}$ cohort, all the rare variants identified in potential candidate genes are found in a heterozygous state. Interestingly, DCC was the only candidate gene for which mutations were inherited autosomal dominantly related to a $\mathrm{CHH}$-associated phenotype [CMM, (18)]. According to the literature related to the associated phenotype of orthologous mouse genes, we found that Dcc heterozygous knockout mice exhibit impaired GnRH neuron migration (19-21). Overall, these evidences prioritized DCC as a novel candidate gene implicated in $\mathrm{CHH}$.

\section{CHH probands harbor rare sequence variants in DCC and its ligand NTN1}

After prioritizing DCC, we next selected variants from within our study population to further evaluate in vitro. This included not only those variants identified and filtered as noted above, but also those with MAF up to $0.5 \%$ in ExAC reference data, given that mutations in other CHH genes with higher MAF up to $0.5 \%$ have been functionally validated for contributing to oligogenic inheritance. Five heterozygous rare sequence variants (RSVs) were identified in DCC (Table 2). Three of these RSVs are found in probands that also have mutations in known $\mathrm{CHH}$ genes (Table 3). Two of them, p.Asn176Ser (N176S) and p.Gly470Asp (G470D), have been 
Table 1. Potential candidate genes encoding FN3-containing protein in $\mathrm{CHH}$

\begin{tabular}{|c|c|c|c|c|c|c|c|}
\hline Gene & $\begin{array}{l}\text { \# rare } \\
\text { variants }\end{array}$ & $\begin{array}{l}\text { \# probands } \\
\text { (KS/nCHH) }\end{array}$ & Phenotype & $\begin{array}{l}\text { Phenotype } \\
\text { MIM number }\end{array}$ & Inheritance & $\begin{array}{l}\text { CNS development } \\
\text { phenotype }^{\mathrm{a}}\end{array}$ & $\begin{array}{l}\text { CHH-associated } \\
\text { phenotype }^{\text {a }}\end{array}$ \\
\hline ANOS1 & 3 & $3(3 / 0)$ & $\begin{array}{l}\text { Hypogonadotropic hypogonad- } \\
\text { ism } 1 \text { with or without anosmia } \\
\text { (Kallmann syndrome 1) }\end{array}$ & 308700 & X-linked & yes & yes \\
\hline CNTN2 & 7 & $12(6 / 6)$ & $\begin{array}{l}\text { Epilepsy, myoclonic, familial } \\
\text { adult, } 5\end{array}$ & 615400 & Autosomal recessive & yes & no \\
\hline DCC & 5 & $7(6 / 1)$ & Mirror movements 1 & 157600 & Autosomal dominant & yes & yes \\
\hline $\mathrm{ROBO} 2$ & 2 & $5(5 / 3)$ & Vesicoureteral reflux 2 & 610878 & - & no & no \\
\hline $\mathrm{ROBO} 3$ & 2 & $4(1 / 3)$ & $\begin{array}{l}\text { Gaze palsy, horizontal, with } \\
\text { progressive scoliosis }\end{array}$ & 607313 & Autosomal recessive & no & yes \\
\hline
\end{tabular}

${ }^{\text {a }}$ Please see Materials and Methods section for a detailed description of these features.

associated with CMM in public variant databases (ClinVar; rs138724679 and rs141813053, respectively) and recent publications (22). p.Gly649Glu (G649E) and p.Ser876Tyr (S876Y) were not found in any of the control cohorts, while the N176S, G470D and p.Pro645Ser (P645S) were present in controls at a low frequency (Table 2). Notably, the N176S DCC variant is significantly enriched in our CHH cohort when compared with ExAC controls $(\mathrm{p}=0.016)$. This variant maps to the second Immunoglobulin-like domain that affects protein stability, while the remaining (G470D, P645S, G649E and S876Y) are located in FN3 domains (Fig. 1A). Interestingly, the S876Y variant maps to the fifth FN3 domain, which is implicated in the interaction of DCC with its ligand Netrin-1, encoded by NTN1 (Fig. 1A). Therefore, we expanded our analysis to include NTN1 and identified two heterozygous variants-p.Arg362Cys (R362C) and p.Thr525Arg (T525R). Both NTN1 variants were absent in the control cohorts, and located in the EGF-like and NTR-like domains, respectively (Table 2, Fig. 1B). All of these missense variants are predicted by at least one protein prediction algorithm as damaging to protein function, and occur in conserved residues suggesting these variants likely impact protein function (Table 2 and Fig. 1).

\section{DCC and NTN1 RSVs cause signaling defects}

In vitro analysis revealed that all identified NTN1 and DCC variants do not impair transcript or protein expression (Fig. 2A and B and Supplementary Material, Figs S2A and S2B, S3). To assess the biological activity of the variants, we first tested the binding properties of DCC and its ligand Netrin-1, as previously described (15). Two DCC variants, N176S and S876Y, displayed impaired binding to wild-type (WT) Netrin-1 (Fig. 2C), while both NTN1 mutants exhibited a significantly reduced binding to DCC-WT (Fig. 2D). The binding of Netrin-1 to the DCC receptor activates several signaling pathways important for cell migration and proliferation, including ERK signaling (23). We used an EGR1-promoter luciferase reporter assay to measure DCC-induced ERK signaling pathway activation (Supplementary Material, Fig. S2C). All NTN1 and DCC variants displayed a significantly decreased EGR1-promoter activation, reflecting a blunted DCC signaling (Fig. 2E and F). These results confirm that our RSVs are indeed loss-of-function mutations, and suggest a pathogenic role in our patients.

\section{DCC mutations lead to cell morphology defects in GnRH neuron cells}

Cell migration relies on the protrusion of actin-rich organelles such as lamellipodia and filopodia as the first and essential step of the cell motility cycle. To further explore the impact of the observed signaling defects on cellular behavior, we examined the effect of DCC mutations in cell morphology of immortalized GnRH neurons (GN11 cells) using immunofluorescence (Fig. 3A and Supplementary Material, Fig. S4). As previously shown in other neuronal cell lines, overexpression of DCC-WT in GN11 cells produced severe morphological changes due to the activation of cytoskeletal remodeling including lamellipodia and filopodia formation (24) (Fig. 3A). Quantitatively, this was reflected by a significant increase in cell spreading (i.e. cell surface area and cell perimeter) and cell shape complexity (i.e. complexity index, CI) in DCC-WT cells compared with control GFP-transfected cells (Fig. 3B and C) without modification of cell polarity (i.e. aspect ratio) (Fig. 3D). Globally, all mutants were unable to reproduce the morphological changes seen with DCC-WT. Indeed, when compared with DCC-WT, three mutants (N176S, G470D and G649E) displayed a significantly lower cell area (Fig. 3B), while all mutants showed a reduction in cell perimeter (Fig. 3C). Finally, all DCC mutants also exhibited significantly reduced induction of cell shape complexity compared with the DCC-WT, revealing a strong defect in the induction of cell protrusions (Fig. 3A and E and Supplementary Material, Fig. S4). Together, these results confirm that the identified DCC mutations significantly impair the cytoskeletal and membrane rearrangement involved in cell protrusions formation, consistent with an impairment of GnRH neuron migration.

\section{NTN1 mutations affect GnRH neuron migration}

To test the impact of NTN1 mutants on immortalized GnRH neurons cell motility, we performed wound healing migration assays using conditioned media (CM) containing WT or mutant recombinant Netrin-1 proteins. As expected, NTN1 WT-CM treatment significantly increased GN11 cell migration by 55\% compared with mock-CM. This effect was significantly impaired for both R362C and T525R NTN1 mutants with a migration rate reduced to the level of mock-CM treated cells (Fig. 3F and J). These results confirm NTN1 RSVs as loss-of-function mutations, and point towards a cell-autonomous role for Netrin-1 in GnRH neuronal migration.

\section{Mutations in DCC and NTN1 are associated with severe GnRH deficiency}

In total, 4 male and 3 female unrelated $\mathrm{CHH}$ probands (7/133) harbor heterozygous DCC and/or NTN1 mutations (Fig. 4, Table 3, 
Table 2. Genotypes and functional in silico prediction of DCC and NTN1 variants found in CHH patients

\begin{tabular}{|c|c|c|c|c|c|c|c|c|c|c|}
\hline & \multirow[b]{2}{*}{$\begin{array}{l}\text { Nucleotide } \\
\text { change }\end{array}$} & \multirow[b]{2}{*}{$\begin{array}{l}\text { Amino acid } \\
\text { change }\end{array}$} & \multirow[b]{2}{*}{$\begin{array}{l}\mathrm{CHH} \\
\text { patients (\%) }\end{array}$} & \multicolumn{2}{|l|}{ MAF (\%) } & \multicolumn{3}{|c|}{ Prediction } & \multirow{2}{*}{$\begin{array}{l}\text { Conservation } \\
\text { GERP }\end{array}$} & \multirow{2}{*}{$\begin{array}{l}\text { Variant-level } \\
\text { association } \\
\text { (P-value) }\end{array}$} \\
\hline & & & & $\begin{array}{l}\text { ExAC } \\
\text { controls }\end{array}$ & $\begin{array}{l}\text { CoLaus } \\
\text { controls }\end{array}$ & PPhen-2 & SIFT & CADD & & \\
\hline \multirow[t]{5}{*}{ DCC } & c. $527 \mathrm{~A}>\mathrm{G}$ & p.Asn176Ser & 0.75 & $<0.005$ & 0.120 & $\mathrm{P}$ & D & $\mathrm{D}$ & 5.71 & 0.016 \\
\hline & c. $1409 \mathrm{G}>\mathrm{A}$ & p.Gly470Asp & 1.5 & $0.320^{\mathrm{a}}$ & 0.370 & $\mathrm{P}$ & $\mathrm{D}$ & $\mathrm{D}$ & 5.4 & 0.170 \\
\hline & c. $1933 \mathrm{C}>\mathrm{T}$ & p.Pro645Ser & 0.75 & 0.019 & - & $\mathrm{D}$ & $\mathrm{D}$ & $\mathrm{D}$ & 5.45 & 0.334 \\
\hline & c.1946G $>$ A & p.Gly649Glu & 0.75 & - & - & B & B & $\mathrm{D}$ & 4.54 & - \\
\hline & c. $2627 \mathrm{C}>\mathrm{A}$ & p.Ser876Tyr & 0.75 & - & - & $\mathrm{P}$ & D & D & 5.42 & - \\
\hline \multirow[t]{2}{*}{ NTN1 } & c. $1084 \mathrm{C}>\mathrm{T}$ & p.Arg362Cys & 0.75 & $<0.001$ & - & $\mathrm{D}$ & D & D & 4.36 & 0.002 \\
\hline & c. $1574 C>G$ & p.Thr525Arg & 0.75 & - & - & B & B & $\mathrm{D}$ & 4.62 & - \\
\hline
\end{tabular}

cDNA and protein changes are based on reference cDNA sequence NM_005215.3 (DCC) and NM_004822.2 (NTN1). CHH cohort included 133 patients. MAF, minor allele frequency; CoLaus, Cohorte Lausannoise study (405 participants)—an ethnically-matched cohort of European controls with detailed phenotypic information (59-62); SIFT, scale-invariant feature transform; PPhen-2, polymorphism phenotyping v2; CADD, Combined Annotation Dependent Depletion; Pr, Private; D, Deleterious or Damaging; P, Possibly damaging: B, Benign. The Genomic Evolutionary Rate Profiling (GERP) score was obtained from the GERP website in September of 2011. It ranges from -12.3 to 6.17 , with 6.17 being the most conserved. Variant-level association in CHH cases vs. ExAC controls were performed with a two-sided Fisher's exact test. ${ }^{a}$ Although not meeting the MAF criteria, this variant was included as it was inherited in a digenic fashion with the NTN1 T525R variant.

Supplementary Material). One mutation was de novo (Family 7), and 3 out of 7 cases the mutation was inherited from an unaffected parent (Families 1, 2, and 3). In the remaining three families, no parental DNA was available for testing (Families 4, 5, and 6). Notably, all probands had severe GnRH deficiency with absent puberty, and all males had a history of micropenis with/without cryptorchidism. The majority of probands harboring mutations in DCC had been diagnosed with KS based on abnormal olfactory function (5/7). This includes a neonatal KS proband (Family 2, Subject II-1) who was unable to complete formal smell testing, however cranial MRI revealed unilateral right olfactory bulb agenesis consistent with $\mathrm{KS}$.

Additional $\mathrm{CHH}$-associated phenotypes were highly variable (Table 3 and Supplementary Material) including CMM (probands in families 1 and 2); bilateral sensorineural hearing loss confirmed by audiogram (proband in family 4); mild facial asymmetry with unilateral auricular hyperplasia (proband family 1); and developmental delay and a mid-brain malformation (cavum septum pellucidum, proband family 2). Three of the 7 probands with DCC/NTN1 mutations are obese, one has confirmed glucose intolerance, and two presented with reduced bone density (osteopenia/osteoporosis).

Family members were available for genetic analysis in five cases and revealed asymptomatic carriers consistent with reduced penetrance in families 1, 2 and 3 (Fig. 4). Mutations in other $\mathrm{CHH}$ loci in addition to the DCC/NTN1 mutations (oligogenicity) were identified in 3/7 families (Fig. 4, Table 3). In Pedigree 1, the proband and the unaffected brother exhibit digenicity with mutations in DCC (N176S), as previously associated with CMM (22), and a known founder mutation in PROKR2 (p.Leu173Arg) (25). The proband in Pedigree 3 harbors mutations in CHD7 (p.Tyr1616Cys) and SEMA3A (p.Arg66Trp) in addition to DCC (G649E). All of the mutations in known $\mathrm{CHH}$ genes are predicted to be deleterious in silico, and two of them (PROKR2 p.Leu173Arg and SEMA3A p.Arg66Trp) have been previously demonstrated to be loss-of-function by in vitro experiments (Table 3) (26-28). In family 2, paternal DNA was not available, however the presence of an asymptomatic carrier together with the CMM observed in the proband are consistent with the previously described incomplete penetrance of the observed DCC mutation in CMM (29). In family 4 and 6, parental DNAs were unavailable, however several evidences suggest an oligogenic inheritance including the presence of milder phenotypes in both paternal and maternal families (Family 4) or the presence of an additional NTN1 mutation (Family 6) (Fig. 4). The proband in Pedigree 7 harbors a de novo NTN1 mutation and a previously reported homozygous frameshift mutation in GNRH1 (30).

\section{DCC and Netrin-1 are expressed in human GnRH neurons and fetal olfactory system}

Several lines of evidence implicate DCC and NTN1 as two novel genes involved in $\mathrm{CHH}$ pathogenesis: (i) $\mathrm{CHH}$ probands harbor rare mutations in DCC and/or its ligand NTN1, (ii) mutations in DCC and NTN1 are associated with defects in cell protrusion formation and cell migration, and iii) Dcc and Ntn1 deficient mice exhibit impaired GnRH neuron migration $(19,20)$.

To further support the biological function of DCC and NTN1 in GnRH neuron migration in humans, we evaluated their expression patterns in GnRH neurons and along their migratory route during human fetal development at the $10^{\text {th }}$ gestational week (10 GW) (see schematic in Fig. 5A). Triple-immunofluorescence staining of coronal sections of $10 \mathrm{GW}$ fetuses $(n=2)$ revealed that Netrin-1 and DCC are expressed in the developing vomeronasal organ (VNO) (Fig. $5 \mathrm{~B}$ and $\mathrm{C}$ ), the surrounding tissue extending from the VNO towards the forebrain (Fig. 5B and C), and in GnRH neurons (Fig. 5D-I). Moreover, Netrin-1 was also expressed in other cell types belonging to the migratory mass-a heterogeneous population of placode-derived and neural crest-derived migratory cells (31-35), (Fig. 5F and H). We further evaluated whether Netrin-1 and DCC expression was retained by GnRH neurons that entered the brain, however at this developmental stage Netrin-1 was too heavily expressed in the forebrain to properly assess its expression and distribution specifically in GnRH neurons (data not shown).

\section{Discussion}

We performed WES in a large cohort of $\mathrm{CHH}$ probands $(n=133)$ and their family members (when available) focusing on genes encoding FN3-domain proteins involved in axonal guidance to identify DCC and NTN1 as candidate genes for CHH. In addition 


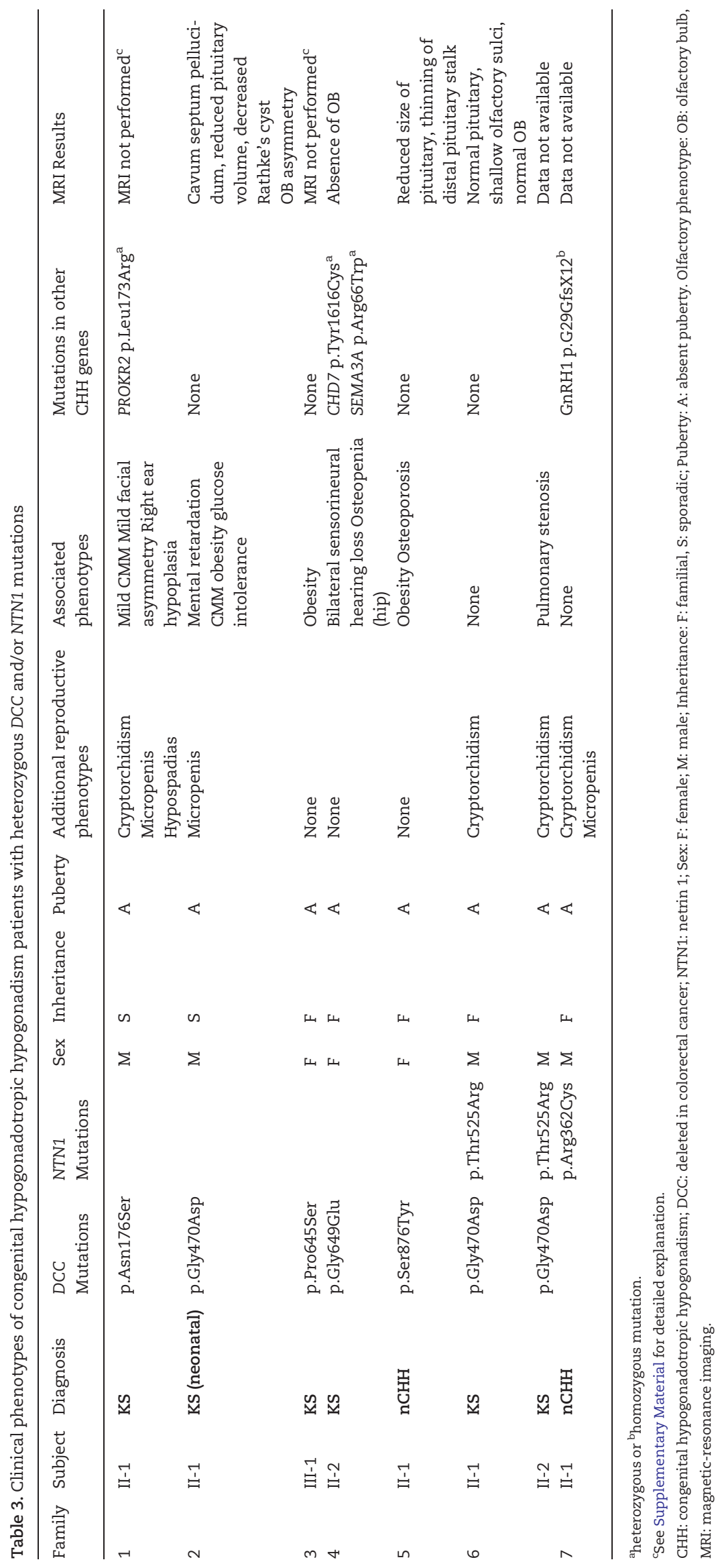




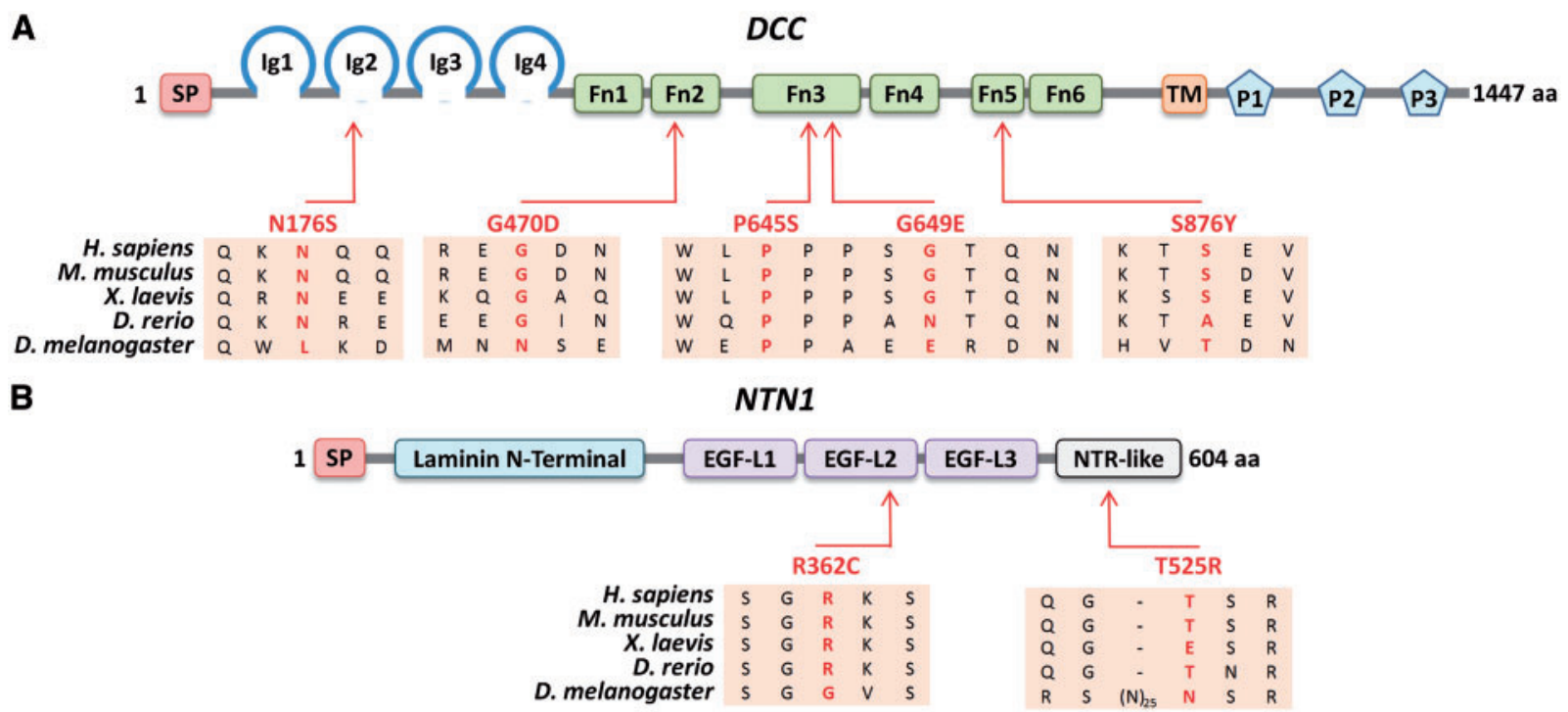

Figure 1. Mapping of DCC and Netrin-1 variants to protein domains. (A,B) Schematic representation of DCC (A) and NTN1 (B) and sequence alignment of amino acid variants from D. melanogaster to H. sapiens. SP: Signal peptide; Ig: Immunoglobulin domain; Fn: Fibronectin domain; TM: Transmembrane domain; EGF-L: EGF-like domain; NTR-like: Netrin-like domain.

A

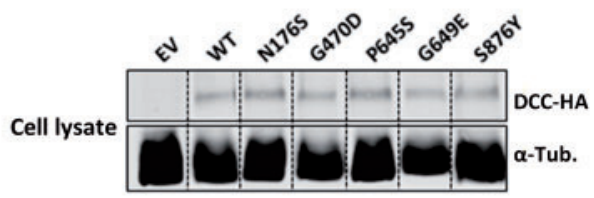

C

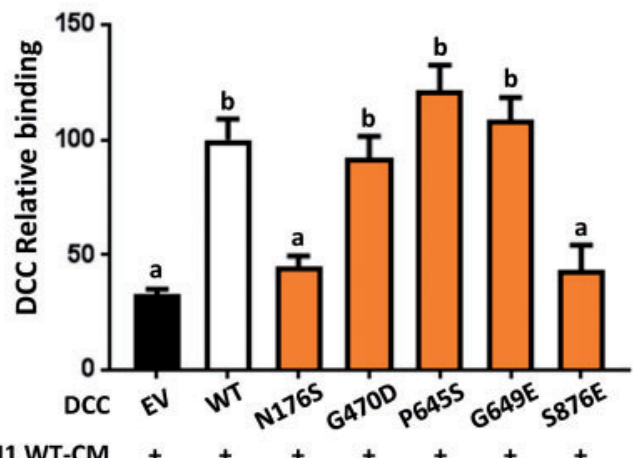

E

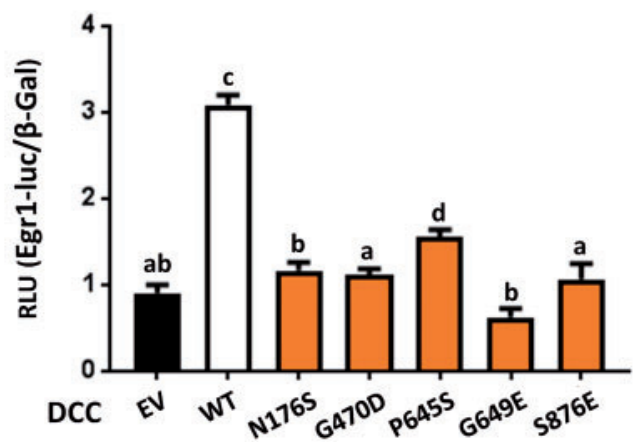

B

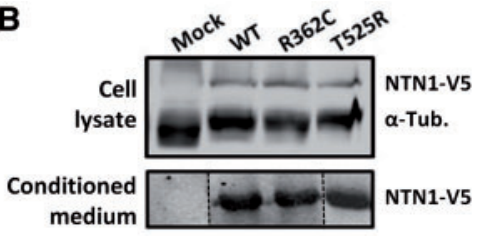

D

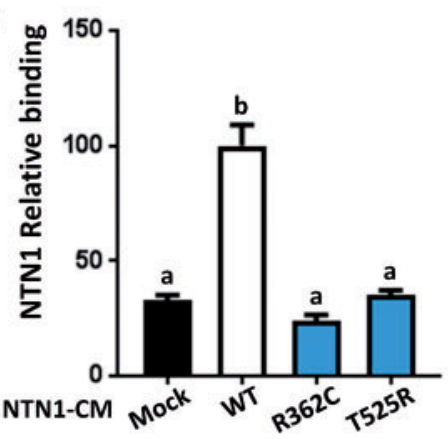

$\mathbf{F}$

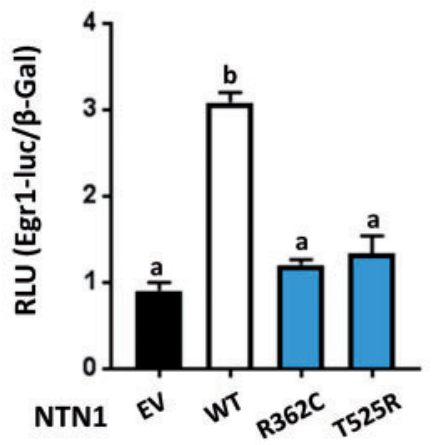

Figure 2. Signaling potency of DCC and Netrin-1 variants. (A) Western blot showing DCC-HA protein expression in transiently transfected CHO cells. (B) Western blot showing V5 tag Netrin-1 protein (NTN1-V5) expression in cell lysates and in conditioned media (CM) in transiently transfected CHO cells. (C) Analysis of Netrin-1 binding with the WT or variant DCC receptors. CHO cells are transfected with plasmid encoding DCC-WT or variants. 48h post-transfection, transfected cells are treated whit Netrin-1 WT or Mock-CM. ELISA assays showing the binding of DCC/Netrin-1 is visualized by absorbance, and expressed in relative units. (D) Analysis of WT and mutants Netrin-1 binding. Cells are transfected with plasmid encoding NTN1-WT, mutants or empty vector. 24h post-transfection, we collected the supernatant (conditioned-medium) which was used to stimulate CHO transiently transfected cells with DCC-WT. ELISA assays showing the binding of DCC/Netrin-1 is visualized by absorbance, and expressed in relative units. (E, F) Transcription reporter assay of WT and mutated DCC or Netrin-1. CHO cells were transiently cotransfected with or without DCC, Netrin-1, EGR1-luciferase reporter and B-galactosidase plasmid. ERK signaling is shown as luciferase activity above baseline, defined as the activity observed with the empty vector alone (black box). Results are presented as mean \pm SEM of 3 independent experiments each performed in sextuplicate. Statistical significance was evaluated with one way ANOVA followed by Tukey's post hoc test. Different letters indicate significant differences between groups $(P<0.05)$. 
A
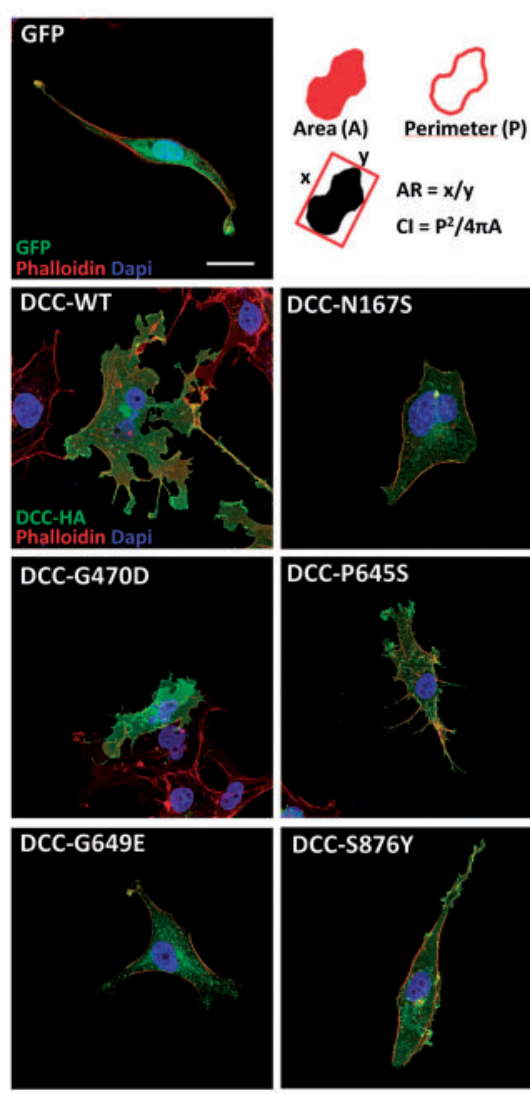
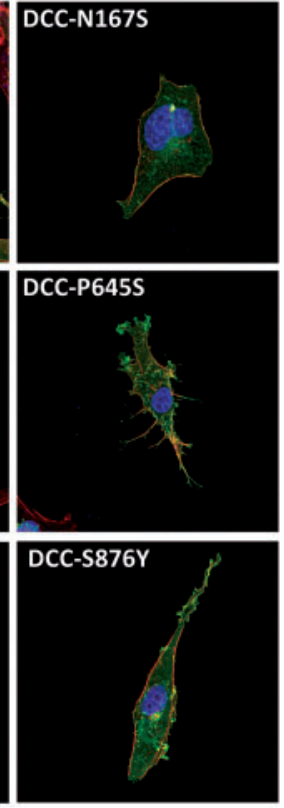

B

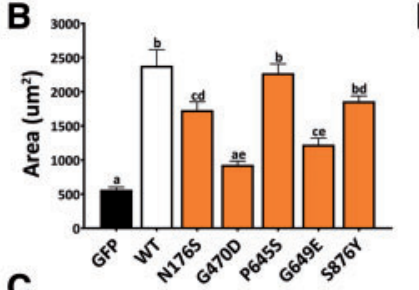

C
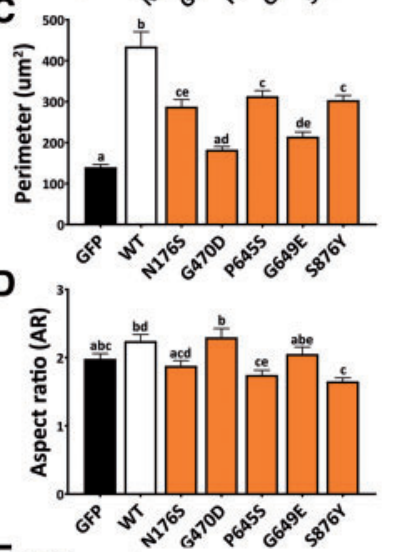

E

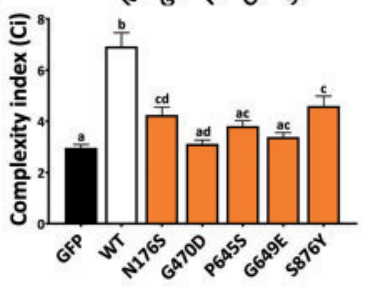

F

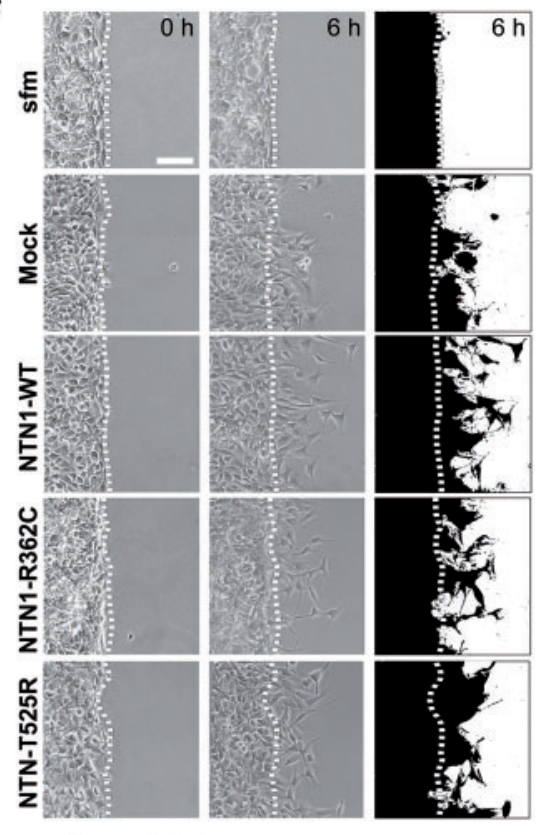

G

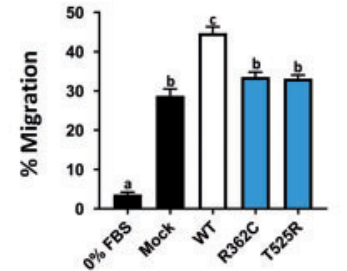

Figure 3. Effect of DCC and Netrin-1 on morphometric aspects and migration in GN11 cells. (A) Immunocytofluorescence of DCC in GN11 cells. GN11 cells are transfected with GFP or DCC plasmid. Twenty-four hours post-transfection, cells are plated onto poly-lysine coated coverslips for 24h. Cells are stained for DCC (green), phalloidin (red), nucleus (blue). (B-E) Quantification of cell area, cell perimeter, aspect ratio and complexity index in GN11-cells transfected with indicated plasmids. $\mathrm{n} \approx 100$ cells per mutants. A: area, P: perimeter, x: major axis, y: minor axis, AR: aspect ratio and CI: Complexity index. Results reflect three independent experiments. Error bars represent SEM, $P<0.01$. Different letters indicate significant difference between groups. (F) Migration assays were performed on GN11 cells stimulated with FBSfree medium, Mock-CM or Netrin-1-CM. Images were taken $0 \mathrm{~h}$ and $6 \mathrm{~h}$ after treatment, image in black and white corresponding to binarized image use to determine the percentage of migration. (G) Percentage of GN11 migration after treatment with or without Netrin-1. Results are presented as mean \pm SEM of 3 independent experiments each performed in sextuplicate. Statistical significance was evaluated with one way ANOVA followed by Tukey's post hoc test. Different letters indicate significant differences between groups $(P<0.05)$.

to demonstrating Netrin-1 and DCC expression along the GnRH migratory pathway in human fetal development, we report the first clinical cases of $\mathrm{CHH}$ patients $(n=6)$ harboring loss-offunction mutations in DCC, a gene encoding FN3-domain protein, along with two mutations in its ligand, NTN1.

Several lines of evidence support the role of NTN1 and DCC as promising candidate $\mathrm{CHH}$ genes: (I) Netrin-1 and its receptor DCC play a critical role in axonal guidance during brain development $(23,36,37)$; (II) mouse genetic studies showed that both Ntn1 and Dcc are essential for GnRH neuron migration (1921); (III) DCC mutations are also implicated in human CMM $(15,22,38)$, a CHH-associated phenotype (5). Our data exemplify these observations, where DCC and NTN1 distribution along the GnRH neurons migratory route suggests an analogous mechanism in human GnRH neuron migration and vomeronasal axon guidance. The majority of probands $(5 / 6)$ harboring mutations in these genes presented with KS (6.8\% of KS cohort), a condition more frequently associated with developmental defects than normosmic $\mathrm{CHH}$ (5).

Two out of five DCC mutations (N176S, S876Y) and one NTN1 mutation (R362C) are located in regions already known to be critical for structural integrity and/or for binding (39-42), and our experiments confirmed that these mutations abolish the Netrin-1/DCC interaction. Interestingly, although located in a region with unknown function, the T525R NTN1 mutation also displays a clear loss of binding to DCC, suggesting a potentially novel biological function of this NTR-like domain. Consistent with the binding assay results, these mutations showed loss of ERK signaling in vitro. Interestingly, the three remaining DCC mutants (G649E, P645S and G470D) also demonstrated a loss of ERK signaling, however their binding to Netrin-1 was intact which is consistent with a recent report in which artificial DCC mutants with normal binding to Netrin-1 displayed defective signaling (39).

Lamellipodia and filopodia are membrane and actin-based cell protrusions essential for cell migration and neurite outgrowth $(43,44)$. DCC signaling controls both of these cellular processes by promoting lamellipodia and filopodia formation in neuronal cells $(24,45)$. In this respect, our morphological analyses showing that all DCC mutants result in a significant defect in cytoskeleton remodeling provide functional evidence linking DCC mutants with the alteration of cellular structures essential for cell migration and axonal guidance in $\mathrm{GnRH}$ neurons. 

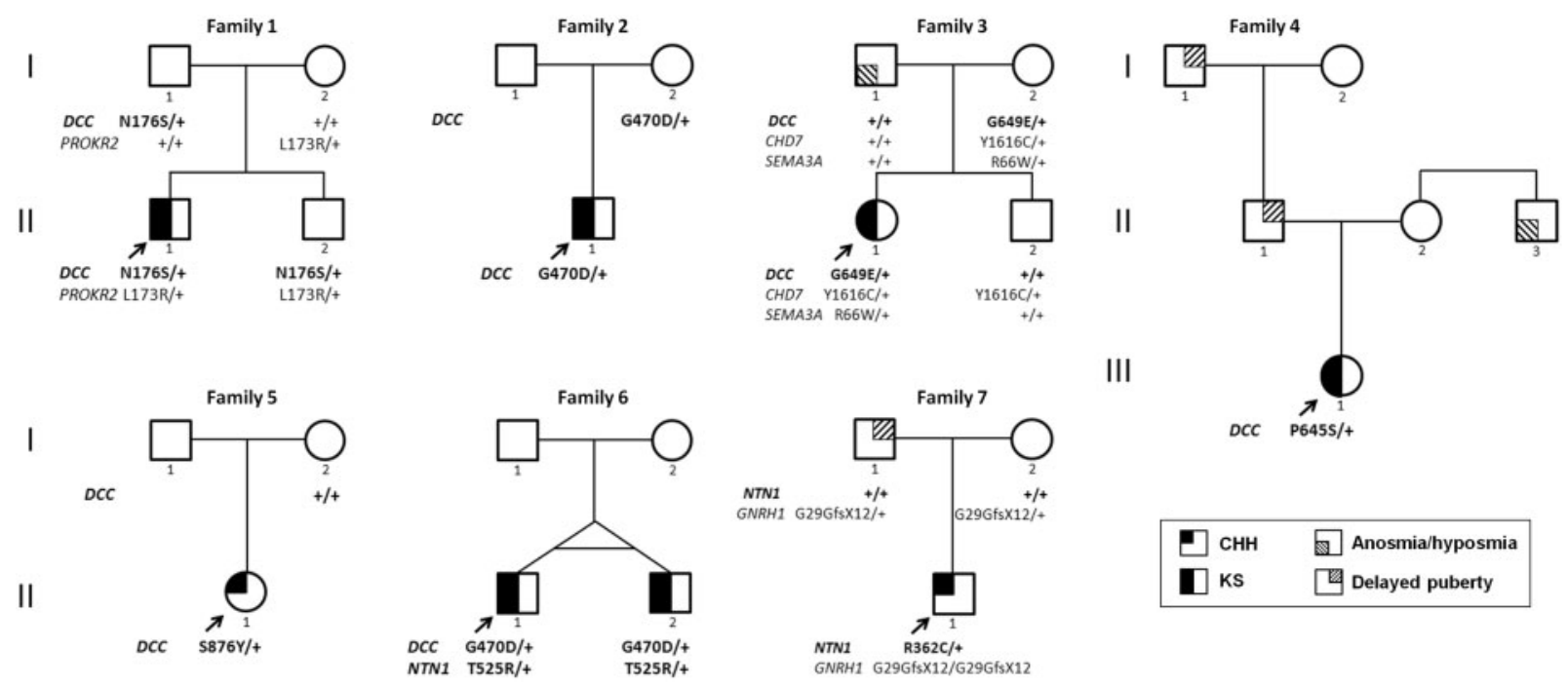

$D C$

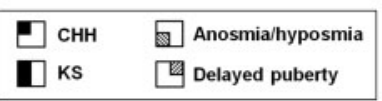

Figure 4. DCC and NTN1 heterozygous variants identified in CHH probands. Pedigrees of CHH probands harboring variations in DCC and Netrin-1. Genotypes are indicated below each individual. Squares depict males, circles depict females and the proband is indicated by an arrow. Solid symbols indicate affected individuals (CHH and KS), while hatched symbols indicate partial phenotypes, as shown in figure legend. The horizontal line connecting siblings in Family 6 indicates monozygotic twins.

Netrin-1 and DCC do not exhibit an exclusive ligand/receptor relationship. Draxin and Cerebelin-4 have been identified as DCC ligands playing a key role in axon guidance $(46,47)$. Similarly, additional receptors such as neogenin, $\alpha 3 \beta 1$-integrin, UNC5b or DSCAM, were described as critical mediators of Netrin-1 effect on cell migration and guidance $(41,48,49)$. Our identified NTN1 mutations also significantly decreased cell migration in immortalized GnRH neurons. Since GN11 cells also express neogenin and $\alpha 3 \beta 1$-integrin [(45) + unpublished observations], it suggests that our NTN1 mutants may also affect these alternative netrin receptors.

DCC and NTN1 are genes known to be involved in axonal guidance during embryonic development as demonstrated by DCC and Netrin-1 null mice exhibiting severe defects of commissural development in the brain and spinal cord with particular defects in axonal projections $(50,51)$. Subsequent studies have shown that DCC/Netrin-1 signaling is essential for the proper development of olfactory/vomeronasal fibers, a scaffold for GnRH neuron migration. Indeed, GnRH neuron migration is profoundly impaired due to the mistargeting of the migratory scaffold in both Dcc and Netrin-1 knockout mice. A similar phenotype has been observed in Dcc \pm and Netrin-1 \pm mice suggesting a gene dosage effect (19-21). These data strongly support the concept that the heterozygote variants found in our patients may be implicated in the physiopathology of CHH. Furthermore, heterozygous mutations in DCC have been previously implicated in CMM $(15,22,38)$, a CHH-associated phenotype (5). Interestingly, a recent report also demonstrated that heterozygote mutations in DCC (protein-truncating mutations) are associated with isolated ACC (agenesis of corpus callosum) with an incomplete penetrance (29). Similarly, biallelic mutations in $D C C$ have recently been found in association with a new genetic syndrome of HGPPS (horizontal gaze palsy, scoliosis), ACC, and midline brainstem cleft (52). The severity (missense vs. protein truncating) and inheritance (heterozygous vs. biallelic) of DCC mutations only partially explains the phenotypic overlap and variability between CMM, ACC, HGPPS and CHH suggesting a significant contribution of additional genetic defects or environmental factors.
The genetic architecture of $\mathrm{CHH}$ is complex, as mutations in most known $\mathrm{CHH}$ genes exhibit incomplete penetrance and variable expressivity both within and between families carrying the same mutations (5). Consistent with this, incomplete penetrance has also been observed for CMM families segregating the N176S and G470D mutations in DCC (22). The CHH families 1 and 2 in the current study harbor these same DCC mutations and also exhibit incomplete penetrance. This is similarly demonstrated by Marsh et al. (29) in regards to DCC mutations in ACC.

Oligogenic inheritance of mutations is observed in the known $\mathrm{CHH}$ genes, and this can at least partially explain the low penetrance and variable expressivity observed both within and across CHH families (8). In particular, we observed mutations in DCC in patients who also harbor pathogenic variants in known $\mathrm{CHH}$ genes. Further, digenic mutations in NTN1 (T525R) and DCC (G470D) were found in monozygotic twins (Family 6) with severe KS associated with cryptorchidism, suggesting a synergistic effect. Finally, based on the incomplete penetrance and the clinical family histories, an oligogenic inheritance implicating the presence of mutations in unknown $\mathrm{CHH}$ loci cannot be ruled out. A particular case of digenic inheritance was observed in family 7. The normosmic proband in this family harbors a de novo NTN1 (R362C) mutation in addition to previously described homozygous GNRH1 mutations (p.Leu30fs) (30). One copy of the GNRH1 mutation is inherited from his asymptomatic mother, and the other is inherited from the father who has a history of delayed puberty. The $\mathrm{nCHH}$ phenotype could be a priori explained by the deleterious genetic defect in GNRH1 gene, however following the The American College of Medical Genetics and Genomics (ACMG) guidelines for the interpretation of sequence variants (53) (absence in control cohort, confirmed in vitro deleterious effect, and de novo inheritance), the NTN1 (R362C) mutation is classified as pathogenic. Combined with the previous studies, our results illustrate the complexity of DCC and Netrin-1 mutations in the genetic architecture of human disorders of axon guidance, and stress the relevance of considering the potential physiopathological consequences of these mutations when providing genetic counseling. 
A GW 10 human fetus
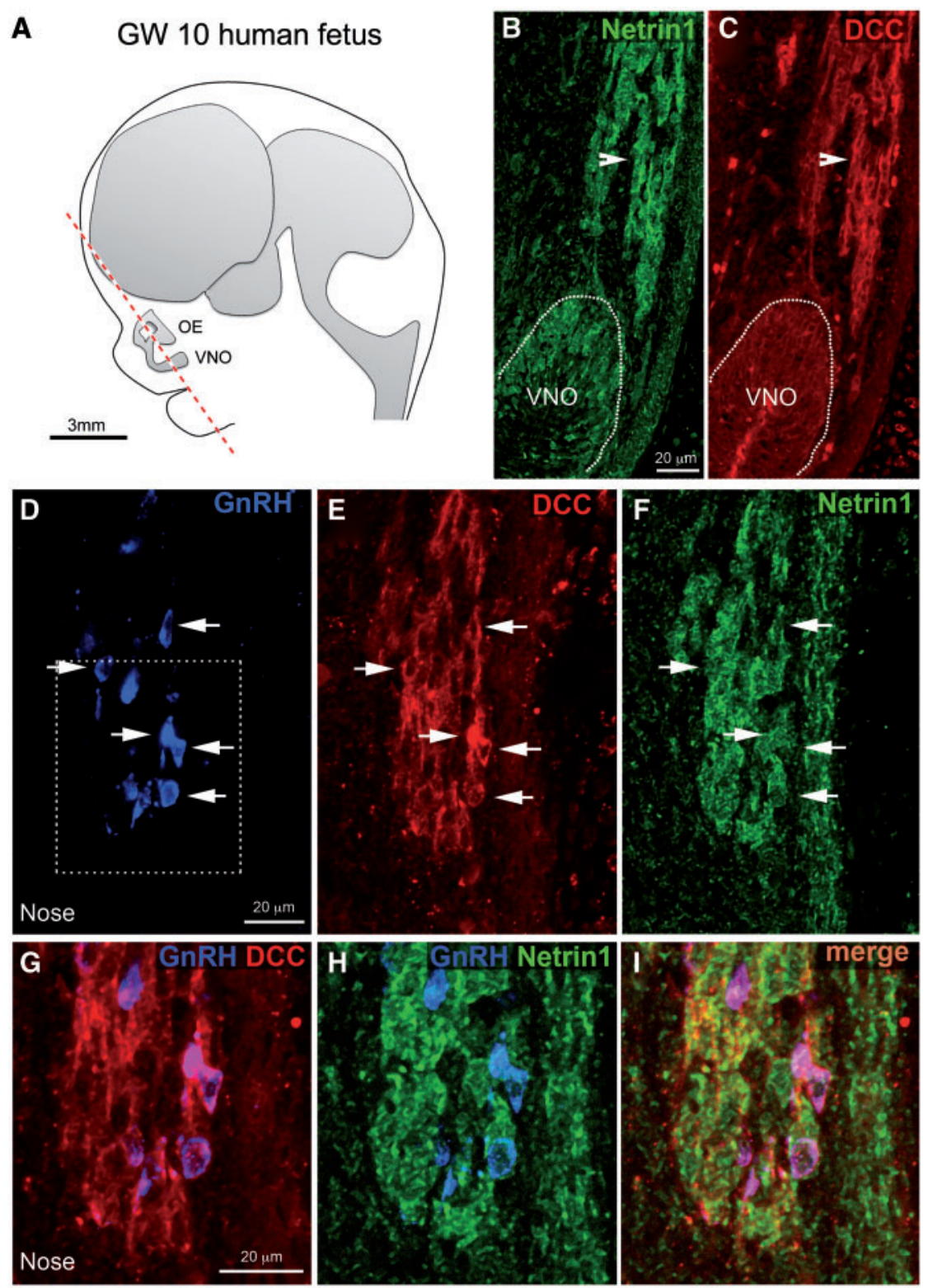

Figure 5. GnRH, Netrin-1 and DCC expression in coronal sections of a GW10 human fetus. (A) Schematic representation of a GW10 human fetus head (sagittal view) illustrating the plane of section (red dotted line) used for immunofluorescence. (B) Netrin-1 (green) is expressed in the VNO. (B,C) Netrin-1 and DCC (red) are both expressed in the VNO and in cells of migratory mass (arrowheads). (D-F) Single-optical confocal planes showing migrating GnRH neurons (blue), (D) co-expressing DCC (E) and Netrin-1 (F). (G-I) High-power photomicrograph of the white box in D, confirming the co-localization of the three antigens. OE: olfactory epithelium. VNO: Vomeronasal organ. Scale bars: $20 \mu \mathrm{m}$.

In summary, we report loss-of-function mutations in DCC, a gene encoding FN3-domain protein, and its ligand, Netrin-1, establishing a mutation prevalence of $5.2 \%$ for these two genes in our CHH cohort. The prevalence of DCC/NTN1 mutations is similar to another FN3-containing gene, ANOS1 (5), suggesting that prevalence of this family of genes is about $10 \%$ in $\mathrm{CHH}$, equivalent to FGF8/FGFR1. The latter were reported as the first genes to be associated with both $\mathrm{KS}$ and nCHH with a prevalence of $10-12 \%(54,55)$. Our findings of (I) high prevalence of DCC/NTN1 mutations in CHH, (II) impaired cytoskeletal reorganization and cell migration induced by signaling defect, and (III) the expression in the developing human GnRH system are consistent with the altered migration of GnRH neurons previously observed in Dcc and Netrin-1 deficient mice models $(19,20)$ and provide a functional link with the phenotype of our $\mathrm{CHH}$ patients. These results further implicate genes encoding FN3-domain protein in the pathophysiology of $\mathrm{CHH}$, and $\mathrm{KS}$ in particular. Finally, this study highlights the clinical relevance of the Netrin-1/DCC pathway in CHH, confirms their essential role in signaling in human GnRH biology, and supports the inclusion of DCC and NTN1 in the list of genes implicated in human CHH.

\section{Materials and Methods}

\section{Subjects}

The CHH cohort included 133 European probands (73 KS and 60 $\mathrm{nCHH}$ ). The diagnosis of $\mathrm{CHH}$ was made on the basis of: I) 
absent or incomplete puberty by 17 years of age; II) low/normal gonadotropin levels in the setting of low serum testosterone/estradiol levels; and III) otherwise normal anterior pituitary function and normal imaging of the hypothalamic-pituitary area (56). Olfaction was assessed by self-report and/or formal testing (57). Neonatal $\mathrm{CHH}$ is diagnosed in male infants with micropenis and/or cryptorchidism in the setting of low sex steroid and gonadotropin concentrations during 'minipuberty' (58). When available, family members were included for genetic studies. The control population cohort consisted of 405 participants from the Cohorte Lausannoise (CoLaus) study, recruited and phenotyped as previously described (59-62). This study was approved by the Institutional Review Board of Partners Healthcare and the ethics committee of the University of Lausanne. All participants provided written informed consent prior to study participation.

\section{Genetic studies}

Genomic DNA was extracted from peripheral-blood samples using the Puregene Blood Kit (Qiagen), following the manufacturer's protocol. The coding exons and intronic splice regions ( $\leq 6 \mathrm{bp}$ from the exons) of genes encoding proteins containing FN3-domains, as well as all CHH known genes (5) were analysed by exome sequencing. Exome capture was performed using the SureSelect All Exon capture v2 and v5 (Agilent Technologies, Santa Clara, CA USA) and sequenced on the HiSeq2500 (Illumina, San Diego CA USA) at BGI (BGI, Shenzen, PRC). Raw sequences (fastq files) were analysed using an in-house pipeline that utilizes the Burrows-Wheeler Alignment algorithm (BWA) (63) for mapping the reads to the human reference sequence (GRCh37), and the Genome Analysis Toolkit (GATK) (64) for the detection of single nucleotide variants (SNVs) and insertion/deletions (Indels). The resulting variants for both exome and Sanger sequences were annotated using SnpEff version 4.0 (65) and dbNSFP version 2.9 (66) to calculate MAF and protein functional predictions. Variants were confirmed by Sanger sequencing on both strands with duplicate PCR reactions and are described according to HGVS nomenclature (67).

Exome sequences from all probands were evaluated for mutations in the known $\mathrm{CHH}$ genes as previously described (68). The known genes evaluated are: ANOS1 (NM_000216.2), FGFR1 (NM_023110.2), FGF8 (NM_033163.3), PROKR2 (NM_144773.2), PROK2 (NM_001126128.13), GNRHR (NM_000406.2), GNRH1 (NM_000825.3), KISS1R (NM_032551.4), KISS1 (NM_002256.3), TACR3 (NM_001059.2), TAC3 (NM_013251.3), NSMF (NM_001130969.1), HS6ST1 (NM_004 807.2), DUSP6 (NM_001946.2), FGF17 (NM_003867.2), FLRT3 (NM_198 391.2), IL17RD (NM_017563.3), WDR11 (NM_018117.11), SOX10 (NM_006941.3), FEZF1 (NM_001024613.3), CHD7 (NM_017780.3) and SPRY4 (NM_030964.3)]. In addition, we screened the PLXNA1 gene (NM_032242.3), recently shown to be implicated in CHH (69).

\section{Bioinformatic filtering of rare non-synonymous variants}

A comprehensive list of genes $(n=203)$ encoding proteins containing FN3-domains was extracted from the Prosite database (http://prosite.expasy.org/PS50853, accessed on February 9, 2017) and served as a reference for the subsequent filtering processes (Supplementary Material, Table S1). Genes known to be involved in axon guidance (GO: 0007411, Supplementary Material, Table S2) were selected and prioritized using OMIM database according to their implication in human genetic diseases characterized by clinical features related to alterations in central nervous system neurobiological processes and $\mathrm{CHH}$ associated phenotypes. Data for central nervous system (CNS) phenotype and/or $\mathrm{CHH}$-associated phenotype were obtained from OMIM (http://omim.org/). Nonsense, missense, and splicesite rare variants (MAF $<0.1 \%$ in ExAC controls) identified from exome sequencing were cross-referenced with this list.

The OMIM database (http://omim.org/) was used to investigate the presence of CNS phenotypes and/or CHH-associated phenotypes in humans harboring mutations in the individual candidate genes. A CNS phenotype was considered positive (Table 1) if the 'Gene Function' section of the OMIM entry described functional studies that link defects in the gene to alterations in CNS development processes. CHH-associated phenotypes have been previously described in detail (5), and a positive entry in Table 1 indicates the presence of this feature in humans with mutations in the respective gene. After identifying a candidate gene for further in vitro studies, variants with MAF up to $0.5 \%$ were identified in the $\mathrm{CHH}$ cohort to account for similar MAF's observed for mutations in other $\mathrm{CHH}$ genes that have been functionally validated for contributing to oligogenic inheritance.

\section{In silico prediction}

To assess the possible functional effect of amino acid variants, PolyPhen-2 v.2.2.5 (http://genetics.bwh.harvard.edu/pph2/), SIFT (http://sift.jcvi.org/) and CADD (http://cadd.gs.washington.edu/ info) algorithms were used. Missense RSVs were also evaluated for conservation across species [GERP $++(70)]$.

\section{Collection and processing of human tissues}

Tissues were made available in accordance with French bylaws (Good practice concerning the conservation, transformation and transportation of human tissue to be used therapeutically, published on December 29, 1998). The studies on human fetal tissue were approved by the French agency for biomedical research (Agence de la Biomédecine, Saint-Denis la Plaine, France, protocol $\mathrm{n}^{\circ}$ : PFS16-002). Non-pathological human fetuses (10 weeks post-amenorrhea, $n=2$ ) were obtained from voluntarily terminated pregnancies after obtaining written informed consent from the parents (Gynecology Department, Jeanne de Flandre Hospital, Lille, France). Fetuses were fixed by immersion in $4 \%$ paraformaldehyde (PFA) at $4{ }^{\circ} \mathrm{C}$ for 3 days. The tissues were then cryoprotected in $30 \%$ sucrose/PBS at $4{ }^{\circ} \mathrm{C}$ overnight, embedded in Tissue-Tek OCT compound (Sakura Finetek, USA), frozen in dry ice and stored at $-80^{\circ} \mathrm{C}$ until sectioning. Frozen samples were cut serially at $20 \mu \mathrm{m}$ using a Leica CM 3050 S cryostat (Leica Biosystems Nussloch GmbH, Germany).

\section{Immunohistochemistry}

Immunohistochemistry for GnRH was performed as previously reported (35) using a guinea pig anti-GnRH (EH\#1018; 1: 10000), produced by Dr. Erik Hrabovszky (Laboratory of Endocrine Neurobiology, Institute of Experimental Medicine of the Hungarian Academy of Sciences, Budapest, Hungary) and previously characterized in post-mortem human hypothalami (71). Antibodies against DCC [Goat IgG, sc-6535; Santa Cruz, (72)] and Netrin-1 [Monoclonal Rat IgG2A; MAB1109; R\&D System, (73)] were used at a dilution of 1: 500. Samples were rinsed in TBS (TRIS buffer saline, $\mathrm{pH}$ 7.6) and subsequently blocked for 2-h at room temperature in blocking solution (TBS $+0.3 \%$ Triton X-100; 
Sigma), 0.25\% BSA (Bovine Serum Albumin; Sigma) and 10\% normal donkey serum (D9663; Sigma). Sections were incubated in a cocktail of primary antibodies (guinea pig anti-GnRH, rat antiNetrin-1, goat anti-DCC) diluted in blocking solution for $48 \mathrm{~h}$ at $4{ }^{\circ} \mathrm{C}$. Sections were then rinsed in TBS and incubated in a cocktail of fluorochrome-conjugated secondary antibodies (all raised in donkey; Alexa-Fluor 488-, 568-, 647-conjugated secondary antibodies; Molecular Probes, Invitrogen) diluted at 1: 400 in TBS for $2 \mathrm{~h}$ at room temperature. Sections were then rinsed in TBS, coverslipped with Mowiol, and imaged using an inverted laser scanning Axio observer confocal microscope (LSM 710, Zeiss; Imaging Core Facility of IFR114 of the University of Lille 2, France).

\section{Molecular characterization of DCC and NTN1 variants}

Plasmids

pCMV-hDCC-HA and pCMV-hNTN1-V5 was obtained from Addgene. All variants were generated using QuickChange XLII Kit (Stratagene) and confirmed by Sanger sequencing. Primers flanking the mutations (available upon request) were used for subsequent PCR amplifications $\left(5^{\prime} \rightarrow 3^{\prime}\right)$.

\section{Cell culture and transfection}

CHO and COS7 cells were grown in DMEM-F12 and DMEM-high glucose medium, respectively, and supplemented with $10 \%$ fetal bovine serum (FBS), 1\% L-glutamine and antibiotics (Gibco, Carlsbad, CA, USA) in humidified air containing $5 \% \mathrm{CO}_{2}$ at $37^{\circ} \mathrm{C}$. Transient transfections of cells were carried out using FuGENE 6 reagent (Promega), according to the manufacturer's protocol.

\section{Protein expression}

After transient transfection in CHO cells, protein expression of tagged WT and mutated proteins was detected by Western blotting. Briefly, cells were lysed in RIPA buffer and separated with $8 \%$ sodium dodecyl sulphate-polyacrylamide gel electrophoresis (SDS-PAGE), followed by electro-transfer onto a nitrocellulose membrane. For immunoblotting, the membranes were probed overnight at $4{ }^{\circ} \mathrm{C}$ with anti-HA (Roche) and anti-V5 (Invitrogen) antibodies and then incubated with appropriate infrared fluorescent secondary antibodies (Licor).

\section{RNA expression}

Total RNAs were extracted from $\mathrm{CHO}$ cells after transient transfection using Trizol reagent (Ambion) according to the manufacturer's recommendations and processed for RT-PCR as previously described (74).

\section{Transcriptional assays}

Cells were transfected with plasmids encoding the different WT and mutant DCCs, Netrin-1, appropriate firefly luciferase reporters, and $\beta$-Galactosidase (internal control) in 96-well plates, using the FuGENE 6 transfection reagent (Promega). Luciferase activity was measured using NOVOstar (BMG LABTECH), normalized to $\beta$-galactosidase activity and analysed using Synergy ${ }^{\mathrm{TM}} \mathrm{Mx}$ (BioTek). All experiments were performed three times in sextuplicates and are expressed as relative light units (RLU).

\section{Binding assays}

Briefly, COS7 cells were plated in 24-well dishes and cultured in DMEM-high glucose supplemented with 10\% FBS and penicillin/ streptomycin. After $24 \mathrm{~h}$, cells were transfected with $1 \mu \mathrm{g}$ of control vector, pCMV-hDCC-HA WT or mutants using Lipofectamine 2000 reagent (Invitrogen). Culture medium was removed $24 \mathrm{~h}$ after transfection and replaced by Netrin-1-V5 protein in DMEM; $10 \% \mathrm{FBS}$ for $2 \mathrm{~h}$ at $37^{\circ} \mathrm{C}$. Cells were then washed, fixed 5 min with $4 \%$ PFA, blocked using PBS-10\% goat serum, and permeabilized with $0.1 \%$ triton X-100. Bound Netrin1-V5 protein was detected using a monoclonal primary antibody (Invitrogen) in 10\% goat serum-PBS and a horseradish peroxidase (HRP)-conjugated goat anti-mouse secondary antibody in $1 \%$ goat serum-PBS (Thermo Fisher). HRP activity was measured using SigmaFast OPD peroxidase substrate (Sigma) and read at $492 \mathrm{~nm}$ using a microplate spectrophotometer. The signal is calculated relative to protein concentration.

\section{Functional characterization of DCC and NTN1 mutants Immunocytofluorescence}

GN11 cells were grown in DMEM-high glucose supplemented with $10 \%$ FBS and penicillin/streptomycin. Briefly, after $48 \mathrm{~h}$ of transfection with the expression vectors coding for DCC-HA WT and mutants, cells were fixed with $4 \%$ paraformaldehyde, permeabilized for 15 min with $0.1 \%$ Triton X100 in PBS and blocked with Superblock 100\% (Invitrogen) for $20 \mathrm{~min}$. Cells were then incubated for $2 \mathrm{~h}$ at room temperature with an anti-HA antibody (Sigma), followed by $1 \mathrm{~h}$ incubation with an anti-rat Alexa 488coupled secondary antibody (Life Technologies). After primary and secondary antibody labeling, cells were incubated with anti-phalloidin-594 (Thermo Scientific) and coverslips were mounted on slides with Fluoromont $\mathrm{G}^{\mathrm{TM}}$ with DAPI (Interchim).

\section{Image acquisition and morphological analysis}

Confocal images were acquired using a Zeiss LSM 780 Quasar inverted microscope (Plan Apochromat 63x/1.40 NA/oil immersion). For morphological analysis, images were taken using a Nikon Eclipse 90i microscope (CFI Plan Fluor 20x: N.A. 0.50; W.D. $2.1 \mathrm{~mm}$ ). ImageJ was used to analyse the cell spreading (cell surface area and cell perimeter) and aspect ratio (cell polarity) of WT and mutants DCC. To quantify the effect of DCC-WT or mutants on cytoskeleton/membrane plasticity, as lamellipodia and filopodia formation, we used imageJ to measure the CI with a morphological parameter measuring cell surface and perimeter roughness as defined in Figure 3.

\section{Migration assays}

GN11 cells were plated in 6-wells with silicone reservoirs separated by a $500 \mu \mathrm{m}$ thick wall (Ibidi) and incubated $24 \mathrm{~h}$ in serum-containing medium. After $2 \mathrm{~h}$ of serum starvation, Ibidi chambers were removed to create a wound field and cells incubated with FBS-free medium, Mock-CM; Netrin-1-WT-CM or Netrin-1 T525R-CM for $6 \mathrm{~h}$. Images were acquired at different time points using a Nikon TS100 inverted microscope (CFI Plan Fluor DL 10x: N.A. 0.30, W.D. $15.2 \mathrm{~mm}$ ), and cell migration quantified as previously reported (75).

\section{Statistics}

PRISM 7 software (GraphPad) was used for statistical analysis (one way ANOVA followed by Tukey's post hoc test). Data are shown as mean \pm SEM and $P$ values $<0.05$ were considered to be statistically significant.

\section{Supplementary Material}

Supplementary Material is available at HMG online. 


\section{Acknowledgements}

We thank the patients and their family members who generously participated in the genetic studies.

Conflict of Interest statement. None declared.

\section{Funding}

The Swiss National Science Foundation (NP) (grant \# 310030_173260), Bourse de Recherche en Endocrinologie SFE 2015 (JB); Institut National de la Sante et de la Recherche Medicale, INSERM, France (grant number U1172); Agence Nationale de la Recherche, ANR, France (ANR-14-CE12-0015-01 RoSes and GnRH to P.G.) (BT and PG)

\section{References}

1. Gore, A.C. GnRH: The Master Molecule of Reproduction: Springer US; 2002.

2. Wray, S. (2010) From nose to brain: development of gonadotrophin-releasing hormone-1 neurones. J. Neuroendocrinol., 22, 743-753.

3. Schwanzel-Fukuda, M. and Pfaff, D.W. (1989) Origin of luteinizing hormone-releasing hormone neurons. Nature, 338, 161-164.

4. Wierman, M.E., Kiseljak-Vassiliades, K. and Tobet, S. (2011) Gonadotropin-releasing hormone ( $\mathrm{GnRH}$ ) neuron migration: initiation, maintenance and cessation as critical steps to ensure normal reproductive function. Front. Neuroendocrinol., $32,43-52$.

5. Boehm, U., Bouloux, P.M., Dattani, M.T., de Roux, N., Dode, C., Dunkel, L., Dwyer, A.A., Giacobini, P., Hardelin, J.P., Juul, A. et al. (2015) Expert consensus document: European Consensus Statement on congenital hypogonadotropic hypogonadism-pathogenesis, diagnosis and treatment. Nat. Rev. Endocrinol., 11, 547-564.

6. Ballabio, A. and Camerino, G. (1992) The gene for X-linked Kallmann syndrome: a human neuronal migration defect. Curr. Opin. Genet. Dev., 2, 417-421.

7. Mitchell, A.L., Dwyer, A., Pitteloud, N. and Quinton, R. (2011) Genetic basis and variable phenotypic expression of Kallmann syndrome: towards a unifying theory. Trends Endocrinol. Metab., 22, 249-258.

8. Pitteloud, N., Quinton, R., Pearce, S., Raivio, T., Acierno, J., Dwyer, A., Plummer, L., Hughes, V., Seminara, S., Cheng, Y.Z. et al. (2007) Digenic mutations account for variable phenotypes in idiopathic hypogonadotropic hypogonadism. J. Clin. Invest., 117, 457-463.

9. Sykiotis, G.P., Plummer, L., Hughes, V.A., Au, M., Durrani, S., Nayak-Young, S., Dwyer, A.A., Quinton, R., Hall, J.E., Gusella, J.F. et al. (2010) Oligogenic basis of isolated gonadotropin-releasing hormone deficiency. Proc. Natl Acad. Sci. U S A, 107, 15140-15144.

10. Legouis, R., Hardelin, J.P., Levilliers, J., Claverie, J.M., Compain, S., Wunderle, V., Millasseau, P., Le Paslier, D., Cohen, D. and Caterina, D. (1991) The candidate gene for the $\mathrm{X}$-linked Kallmann syndrome encodes a protein related to adhesion molecules. Cell, 67, 423-435.

11. de Castro, F., Esteban, P.F., Bribian, A., Murcia-Belmonte, V., Garcia-Gonzalez, D. and Clemente, D. (2014) The adhesion molecule anosmin-1 in neurology: Kallmann syndrome and beyond. Adv. Neurobiol., 8, 273-292.

12. Salian-Mehta, S., Xu, M., Knox, A.J., Plummer, L., Slavov, D., Taylor, M., Bevers, S., Hodges, R.S., Crowley, W.F., Jr. and
Wierman, M.E. (2014) Functional consequences of AXL sequence variants in hypogonadotropic hypogonadism. J. Clin. Endocrinol. Metab., 99, 1452-1460.

13. Miraoui, H., Dwyer, A.A., Sykiotis, G.P., Plummer, L., Chung, W., Feng, B., Beenken, A., Clarke, J., Pers, T.H., Dworzynski, P. et al. (2013) Mutations in FGF17, IL17RD, DUSP6, SPRY4, and FLRT3 are identified in individuals with congenital hypogonadotropic hypogonadism. Am. J. Hum. Genet., 92, 725-743.

14. Vits, L., Van Camp, G., Coucke, P., Fransen, E., De Boulle, K., Reyniers, E., Korn, B., Poustka, A., Wilson, G. and SchranderStumpel, C. (1994) MASA syndrome is due to mutations in the neural cell adhesion gene L1CAM. Nat. Genet., 7, 408-413.

15. Srour, M., Riviere, J.B., Pham, J.M., Dube, M.P., Girard, S., Morin, S., Dion, P.A., Asselin, G., Rochefort, D., Hince, P. et al. (2010) Mutations in DCC cause congenital mirror movements. Science, 328, 592.

16. Marsh, A.P., Heron, D., Edwards, T.J., Quartier, A., Galea, C., Nava, C., Rastetter, A., Moutard, M.L., Anderson, V., Bitoun, P. et al. (2017) Mutations in DCC cause isolated agenesis of the corpus callosum with incomplete penetrance. Nat Genet, 49, 511-514.

17. Schraders, M., Oostrik, J., Huygen, P.L., Strom, T.M., van Wijk, E., Kunst, H.P., Hoefsloot, L.H., Cremers, C.W., Admiraal, R.J. and Kremer, H. (2010) Mutations in PTPRQ are a cause of autosomal-recessive nonsyndromic hearing impairment DFNB84 and associated with vestibular dysfunction. Am. J. Hum. Genet., 86, 604-610.

18. Costa-Barbosa, F.A., Balasubramanian, R., Keefe, K.W., Shaw, N.D., Al-Tassan, N., Plummer, L., Dwyer, A.A., Buck, C.L., Choi, J.H., Seminara, S.B. et al. (2013) Prioritizing genetic testing in patients with Kallmann syndrome using clinical phenotypes. J. Clin. Endocrinol. Metab., 98, E943-E953.

19. Schwarting, G.A., Kostek, C., Bless, E.P., Ahmad, N. and Tobet, S.A. (2001) Deleted in colorectal cancer (DCC) regulates the migration of luteinizing hormone-releasing hormone neurons to the basal forebrain. J. Neurosci., 21, 911-919.

20. Schwarting, G.A., Raitcheva, D., Bless, E.P., Ackerman, S.L. and Tobet, S. (2004) Netrin 1-mediated chemoattraction regulates the migratory pathway of LHRH neurons. Eur. J. Neurosci., 19, 11-20.

21. Lakhina, V., Marcaccio, C.L., Shao, X., Lush, M.E., Jain, R.A., Fujimoto, E., Bonkowsky, J.L., Granato, M. and Raper, J.A. (2012) Netrin/DCC signaling guides olfactory sensory axons to their correct location in the olfactory bulb. J. Neurosci., 32, 4440-4456.

22. Meneret, A., Depienne, C., Riant, F., Trouillard, O., Bouteiller, D., Cincotta, M., Bitoun, P., Wickert, J., Lagroua, I., Westenberger, A. et al. (2014) Congenital mirror movements: mutational analysis of RAD51 and DCC in 26 cases. Neurology, 82, 1999-2002.

23. Cirulli, V. and Yebra, M. (2007) Netrins: beyond the brain. Nat. Rev. Mol. Cell Biol., 8, 296-306.

24. Shekarabi, M. and Kennedy, T.E. (2002) The netrin-1 receptor DCC promotes filopodia formation and cell spreading by activating Cdc42 and Rac1. Mol. Cell Neurosci., 19, 1-17.

25. Avbelj Stefanija, M., Jeanpierre, M., Sykiotis, G.P., Young, J., Quinton, R., Abreu, A.P., Plummer, L., Au, M.G., Balasubramanian, R., Dwyer, A.A. et al. (2012) An ancient founder mutation in PROKR2 impairs human reproduction. Hum. Mol. Genet., 21, 4314-4324.

26. Libri, D.V., Kleinau, G., Vezzoli, V., Busnelli, M., Guizzardi, F., Sinisi, A.A., Pincelli, A.I., Mancini, A., Russo, G., Beck-Peccoz, 
P. et al. (2014) Germline prokineticin receptor 2 (PROKR2) variants associated with central hypogonadism cause differental modulation of distinct intracellular pathways. J. Clin. Endocrinol. Metab., 99, E458-E463.

27. Hanchate, N.K., Giacobini, P., Lhuillier, P., Parkash, J., Espy, C., Fouveaut, C., Leroy, C., Baron, S., Campagne, C., Vanacker, C. et al. (2012) SEMA3A, a gene involved in axonal pathfinding, is mutated in patients with Kallmann syndrome. PLoS Genet., 8, e1002896.

28. Balasubramanian, R., Choi, J.H., Francescatto, L., Willer, J., Horton, E.R., Asimacopoulos, E.P., Stankovic, K.M., Plummer, L., Buck, C.L., Quinton, R. et al. (2014) Functionally compromised CHD7 alleles in patients with isolated GnRH deficiency. Proc. Natl Acad. Sci. U S A, 111, 17953-17958.

29. Marsh, A.P., Heron, D., Edwards, T.J., Quartier, A., Galea, C., Nava, C., Rastetter, A., Moutard, M.L., Anderson, V., Bitoun, P. et al. (2017) Mutations in DCC cause isolated agenesis of the corpus callosum with incomplete penetrance. Nat. Genet., 49, 511-514.

30. Chan, Y.M., de Guillebon, A., Lang-Muritano, M., Plummer, L., Cerrato, F., Tsiaras, S., Gaspert, A., Lavoie, H.B., Wu, C.H., Crowley, W.F., Jr. et al. (2009) GNRH1 mutations in patients with idiopathic hypogonadotropic hypogonadism. Proc. Natl Acad. Sci. U S A, 106, 11703-11708.

31. Wray, S., Key, S., Qualls, R. and Fueshko, S.M. (1994) A subset of peripherin positive olfactory axons delineates the luteinizing hormone releasing hormone neuronal migratory pathway in developing mouse. Dev. Biol., 166, 349-354.

32. Tarozzo, G., Peretto, P. and Fasolo, A. (1995) Cell migration from the olfactory placode and the ontogeny of the neuroendocrine compartments. Zoolog. Sci., 12, 367-383.

33. Miller, A.M., Treloar, H.B. and Greer, C.A. (2010) Composition of the migratory mass during development of the olfactory nerve. J. Comp. Neurol., 518, 4825-4841.

34. Forni, P.E., Taylor-Burds, C., Melvin, V.S., Williams, T. and Wray, S. (2011) Neural crest and ectodermal cells intermix in the nasal placode to give rise to GnRH-1 neurons, sensory neurons, and olfactory ensheathing cells. J. Neurosci., 31, 6915-6927.

35. Casoni, F., Malone, S.A., Belle, M., Luzzati, F., Collier, F., Allet, C., Hrabovszky, E., Rasika, S., Prevot, V., Chedotal, A. et al. (2016) Development of the neurons controlling fertility in humans: new insights from 3D imaging and transparent fetal brains. Development, 143, 3969-3981.

36. Hedgecock, E.M., Culotti, J.G. and Hall, D.H. (1990) The unc-5, unc- 6 , and unc- 40 genes guide circumferential migrations of pioneer axons and mesodermal cells on the epidermis in C. elegans. Neuron, 4, 61-85.

37. Keino-Masu, K., Masu, M., Hinck, L., Leonardo, E.D., Chan, S.S., Culotti, J.G. and Tessier-Lavigne, M. (1996) Deleted in Colorectal Cancer (DCC) encodes a netrin receptor. Cell, 87, 175-185.

38. Depienne, C., Cincotta, M., Billot, S., Bouteiller, D., Groppa, S., Brochard, V., Flamand, C., Hubsch, C., Meunier, S., Giovannelli, F. et al. (2011) A novel DCC mutation and genetic heterogeneity in congenital mirror movements. Neurology, 76, 260-264.

39. Chen, Q., Sun, X., Zhou, X.H., Liu, J.H., Wu, J., Zhang, Y. and Wang, J.H. (2013) N-terminal horseshoe conformation of DCC is functionally required for axon guidance and might be shared by other neural receptors. J. Cell Sci., 126, 186-195.

40. Geisbrecht, B.V., Dowd, K.A., Barfield, R.W., Longo, P.A. and Leahy, D.J. (2003) Netrin binds discrete subdomains of DCC and UNC5 and mediates interactions between DCC and heparin. J. Biol. Chem., 278, 32561-32568.
41. Xu, K., Wu, Z., Renier, N., Antipenko, A., Tzvetkova-Robev, D., Xu, Y., Minchenko, M., Nardi-Dei, V., Rajashankar, K.R., Himanen, J., Neural migration. et al. (2014) Structures of netrin-1 bound to two receptors provide insight into its axon guidance mechanism. Science, 344, 1275-1279.

42. Finci, L., Zhang, Y., Meijers, R. and Wang, J.H. (2015) Signaling mechanism of the netrin-1 receptor DCC in axon guidance. Prog. Biophys. Mol. Biol., 118, 153-160.

43. Mattila, P.K. and Lappalainen, P. (2008) Filopodia: molecular architecture and cellular functions. Nat. Rev. Mol. Cell Biol., 9, 446-454.

44. Ridley, A.J. (2011) Life at the leading edge. Cell, 145, 1012-1022.

45. Liu, Y., Peng, Y., Dai, P.G., Du, Q.S., Mei, L. and Xiong, W.C. (2012) Differential regulation of myosin X movements by its cargos, DCC and neogenin. J. Cell Sci., 125, 751-762.

46. Ahmed, G., Shinmyo, Y., Ohta, K., Islam, S.M., Hossain, M., Naser, I.B., Riyadh, M.A., Su, Y., Zhang, S., Tessier-Lavigne, M. et al. (2011) Draxin inhibits axonal outgrowth through the netrin receptor DCC. J. Neurosci., 31, 14018-14023.

47. Haddick, P.C.G., Tom, I., Luis, E., Quiñones, G., Wranik, B.J., Ramani, S.R., Stephan, J.-P., Tessier-Lavigne, M., Gonzalez, L.C. and Key, B. (2014) Defining the ligand specificity of the deleted in colorectal cancer (DCC) receptor. PLoS One, 9, e84823.

48. Stanco, A., Szekeres, C., Patel, N., Rao, S., Campbell, K., Kreidberg, J.A., Polleux, F. and Anton, E.S. (2009) Netrin-1-alpha3beta1 integrin interactions regulate the migration of interneurons through the cortical marginal zone. Proc. Natl Acad. Sci. U S A, 106, 7595-7600.

49. Liu, G., Li, W., Wang, L., Kar, A., Guan, K.L., Rao, Y. and Wu, J.Y. (2009) DSCAM functions as a netrin receptor in commissural axon pathfinding. Proc. Natl Acad. Sci. U S A, 106, 2951-2956.

50. Fazeli, A., Dickinson, S.L., Hermiston, M.L., Tighe, R.V., Steen, R.G., Small, C.G., Stoeckli, E.T., Keino-Masu, K., Masu, M., Rayburn, H. et al. (1997) Phenotype of mice lacking functional Deleted in colorectal cancer (Dcc) gene. Nature, 386, 796-804.

51. Serafini, T., Colamarino, S.A., Leonardo, E.D., Wang, H., Beddington, R., Skarnes, W.C. and Tessier-Lavigne, M. (1996) Netrin-1 is required for commissural axon guidance in the developing vertebrate nervous system. Cell, 87, 1001-1014.

52. Jamuar, S.S., Schmitz-Abe, K., D'Gama, A.M., Drottar, M., Chan, W.M., Peeva, M., Servattalab, S., Lam, A.N., Delgado, M.R., Clegg, N.J. et al. (2017) Biallelic mutations in human DCC cause developmental split-brain syndrome. Nat. Genet., 49, 606-612.

53. Richards, S., Aziz, N., Bale, S., Bick, D., Das, S., Gastier-Foster, J., Grody, W.W., Hegde, M., Lyon, E., Spector, E. et al. (2015) Standards and guidelines for the interpretation of sequence variants: a joint consensus recommendation of the American College of Medical Genetics and Genomics and the Association for Molecular Pathology. Genet. Med., 17, 405-424.

54. Dode, C., Levilliers, J., Dupont, J.M., De Paepe, A., Le Du, N., Soussi-Yanicostas, N., Coimbra, R.S., Delmaghani, S., Compain-Nouaille, S., Baverel, F. et al. (2003) Loss-of-function mutations in FGFR1 cause autosomal dominant Kallmann syndrome. Nat. Genet., 33, 463-465.

55. Pitteloud, N., Acierno, J.S., Jr., Meysing, A., Eliseenkova, A.V., Ma, J., Ibrahimi, O.A., Metzger, D.L., Hayes, F.J., Dwyer, A.A., Hughes, V.A. et al. (2006) Mutations in fibroblast growth factor receptor 1 cause both Kallmann syndrome and 
normosmic idiopathic hypogonadotropic hypogonadism. Proc. Natl Acad. Sci. U S A, 103, 6281-6286.

56. Pitteloud, N., Hayes, F.J., Dwyer, A., Boepple, P.A., Lee, H. and Crowley, W.F. Jr. (2002) Predictors of outcome of long-term $\mathrm{GnRH}$ therapy in men with idiopathic hypogonadotropic hypogonadism. J. Clin. Endocrinol. Metab., 87, 4128-4136.

57. Lewkowitz-Shpuntoff, H.M., Hughes, V.A., Plummer, L., Au, M.G., Doty, R.L., Seminara, S.B., Chan, Y.M., Pitteloud, N., Crowley, W.F., Jr. and Balasubramanian, R. (2012) Olfactory phenotypic spectrum in idiopathic hypogonadotropic hypogonadism: pathophysiological and genetic implications. J. Clin. Endocrinol. Metab., 97, E136-E144.

58. Bouvattier, C., Maione, L., Bouligand, J., Dode, C., GuiochonMantel, A. and Young, J. (2011) Neonatal gonadotropin therapy in male congenital hypogonadotropic hypogonadism. Nat. Rev. Endocrinol., 8, 172-182.

59. Firmann, M., Mayor, V., Vidal, P.M., Bochud, M., Pecoud, A., Hayoz, D., Paccaud, F., Preisig, M., Song, K.S., Yuan, X. et al. (2008) The CoLaus study: a population-based study to investigate the epidemiology and genetic determinants of cardiovascular risk factors and metabolic syndrome. BMC Cardiovasc. Disord., 8, 6.

60. Nelson, M.R., Wegmann, D., Ehm, M.G., Kessner, D., St Jean, P., Verzilli, C., Shen, J., Tang, Z., Bacanu, S.A., Fraser, D. et al. (2012) An abundance of rare functional variants in 202 drug target genes sequenced in 14, 002 people. Science, 337, 100-104.

61. Song, K., Nelson, M.R., Aponte, J., Manas, E.S., Bacanu, S.A., Yuan, X., Kong, X., Cardon, L., Mooser, V.E., Whittaker, J.C. et al. (2012) Sequencing of Lp-PLA2-encoding PLA2G7 gene in 2000 Europeans reveals several rare loss-of-function mutations. Pharmacogenomics J., 12, 425-431.

62. Warren, L.L., Li, L., Nelson, M.R., Ehm, M.G., Shen, J., Fraser, D.J., Aponte, J.L., Nangle, K.L., Slater, A.J., Woollard, P.M. et al. (2012) Deep resequencing unveils genetic architecture of ADIPOQ and identifies a novel low-frequency variant strongly associated with adiponectin variation. Diabetes, 61 , 1297-1301.

63. Li, H. and Durbin, R. (2009) Fast and accurate short read alignment with Burrows-Wheeler transform. Bioinformatics, $25,1754-1760$.

64. DePristo, M.A., Banks, E., Poplin, R., Garimella, K.V., Maguire, J.R., Hartl, C., Philippakis, A.A., del Angel, G., Rivas, M.A., Hanna, M. et al. (2011) A framework for variation discovery and genotyping using next-generation DNA sequencing data. Nat. Genet., 43, 491-498.

65. Cingolani, P., Platts, A., Wang le, L., Coon, M., Nguyen, T., Wang, L., Land, S.J., Lu, X. and Ruden, D.M. (2012) A program for annotating and predicting the effects of single nucleotide polymorphisms, SnpEff: SNPs in the genome of Drosophila melanogaster strain w1118; iso-2; iso-3. Fly (Austin), 6, 80-92.

66. Liu, X., Jian, X. and Boerwinkle, E. (2013) dbNSFP v2.0: a database of human non-synonymous SNVs and their functional predictions and annotations. Hum. Mutat., 34, E2393-E2402.

67. den Dunnen, J.T. and Antonarakis, S.E. (2000) Mutation nomenclature extensions and suggestions to describe complex mutations: a discussion. Hum. Mutat., 15, 7-12.

68. Xu, C., Messina, A., Somm, E., Miraoui, H., Kinnunen, T., Acierno, J., Jr., Niederlander, N.J., Bouilly, J., Dwyer, A.A., Sidis, Y. et al. (2017) KLB, encoding beta-Klotho, is mutated in patients with congenital hypogonadotropic hypogonadism. EMBO Mol. Med., 9,1379-1397.

69. Marcos, S., Monnier, C., Rovira, X., Fouveaut, C., Pitteloud, N., Ango, F., Dode, C. and Hardelin, J.P. (2017) Defective signaling through plexin-A1 compromises the development of the peripheral olfactory system and neuroendocrine reproductive axis in mice. Hum. Mol. Genet., 26, 2006-2017.

70. Davydov, E.V., Goode, D.L., Sirota, M., Cooper, G.M., Sidow, A., Batzoglou, S. and Wasserman, W.W. (2010) Identifying a high fraction of the human genome to be under selective constraint using GERP ++. PLoS Comput. Biol., 6, e1001025.

71. Hrabovszky, E., Molnar, C.S., Sipos, M.T., Vida, B., Ciofi, P., Borsay, B.A., Sarkadi, L., Herczeg, L., Bloom, S.R. and Ghatei, M.A. (2011) Sexual dimorphism of kisspeptin and neurokinin $B$ immunoreactive neurons in the infundibular nucleus of aged men and women. Front. Endocrinol. (Lausanne), 2, 80.

72. Law, C., Schaan Profes, M., Levesque, M., Kaltschmidt, J.A., Verhage, M. and Kania, A. (2016) Normal Molecular Specification and Neurodegenerative Disease-Like Death of Spinal Neurons Lacking the SNARE-Associated Synaptic Protein Munc18-1. J. Neurosci., 36, 561-576.

73. Ramkhelawon, B., Hennessy, E.J., Menager, M., Ray, T.D., Sheedy, F.J., Hutchison, S., Wanschel, A., Oldebeken, S., Geoffrion, M., Spiro, W. et al. (2014) Netrin-1 promotes adipose tissue macrophage retention and insulin resistance in obesity. Nat. Med., 20, 377-384.

74. Bouilly, J., Veitia, R.A. and Binart, N. (2014) NOBOX is a key FOXL2 partner involved in ovarian folliculogenesis. J. Mol. Cell Biol., 6, 175-177.

75. Messina, A., Ferraris, N., Wray, S., Cagnoni, G., Donohue, D.E., Casoni, F., Kramer, P.R., Derijck, A.A., Adolfs, Y., Fasolo, A. et al. (2011) Dysregulation of Semaphorin7A/beta1-integrin signaling leads to defective GnRH-1 cell migration, abnormal gonadal development and altered fertility. Hum. Mol. Genet., 20, 4759-4774. 